\title{
Tracking the rate of initiation and retention on isoniazid preventive therapy in a high human immunodeficiency virus and tuberculosis burden setting of Lesotho
}

\begin{tabular}{|c|c|}
\hline \multicolumn{2}{|c|}{$\begin{array}{l}\text { Authors: } \\
\text { Eltony Mugomeri }{ }^{1} \text { (D) } \\
\text { Dedré Olivier }{ }^{2} \\
\text { Wilhelmiena M.J. van den } \\
\text { Heever }^{2} \text { (D) }\end{array}$} \\
\hline \multicolumn{2}{|c|}{$\begin{array}{l}\text { Affiliations: } \\
{ }^{1} \text { Medical Laboratory Scienc } \\
\text { Africa University, Mutare, } \\
\text { Zimbabwe }\end{array}$} \\
\hline \multicolumn{2}{|c|}{$\begin{array}{l}{ }^{2} \text { Department of Health } \\
\text { Sciences, Central University } \\
\text { of Technology, Bloemfontein, } \\
\text { South Africa }\end{array}$} \\
\hline \multicolumn{2}{|c|}{$\begin{array}{l}\text { Corresponding author: } \\
\text { Eltony Mugomeri, } \\
\text { emugomeri@yahoo.com }\end{array}$} \\
\hline \multicolumn{2}{|c|}{$\begin{array}{l}\text { Dates: } \\
\text { Received: } 07 \text { May } 2019 \\
\text { Accepted: } 07 \text { Oct. } 2019 \\
\text { Published: } 25 \text { Nov. } 2019\end{array}$} \\
\hline \multicolumn{2}{|c|}{$\begin{array}{l}\text { How to cite this article: } \\
\text { Mugomeri E, Olivier D, } \\
\text { Van den Heever WMJ. } \\
\text { Tracking the rate of initiation } \\
\text { and retention on isoniazid } \\
\text { preventive therapy in a high } \\
\text { human immunodeficiency } \\
\text { virus and tuberculosis burden } \\
\text { setting of Lesotho. S Afr J } \\
\text { Infect Dis. } 2019 ; 34(1) \text {, a10. } \\
\text { https://doi.org/10.4102/ } \\
\text { sajid.v34i1.10 }\end{array}$} \\
\hline \multicolumn{2}{|c|}{$\begin{array}{l}\text { Copyright: } \\
\text { (C) 2019. The Authors. } \\
\text { Licensee: AOSIS. This work } \\
\text { is licensed under the } \\
\text { Creative Commons } \\
\text { Attribution License. }\end{array}$} \\
\hline \multicolumn{2}{|l|}{ Read online: } \\
\hline 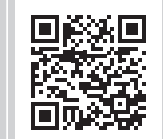 & $\begin{array}{l}\text { Scan this QR } \\
\text { code with your } \\
\text { smart phone or } \\
\text { mobile device } \\
\text { to read online. }\end{array}$ \\
\hline
\end{tabular}

Background: Tuberculosis (TB) remains a public health problem, particularly in people living with human immunodeficiency virus (PLHIV). Yet, efforts to reduce TB incidence using isoniazid preventive therapy (IPT) have been curtailed by poor uptake of this intervention. This study reviewed the rate of IPT initiation in the sub-Saharan country of Lesotho, which has one of the highest TB incidences in the world.

Methods: Time to IPT initiation in randomly sampled medical records of PLHIV was analysed using Cox's proportional hazards regression. Differences in the periods of enrolment into Human immunodeficiency virus (HIV) care were controlled for by considering the year IPT was launched (2011) as the base year and stratifying the medical records into the 2004-2010 cohort (before the launch of IPT) and the 2011-2016 cohort (after the launch).

Results: Out of 2955 patients included in the final analysis, $68.8 \%$ had received IPT by the study exit time. However, the overall rate of IPT initiation was 20.6 per 100 person-years, with $135(6.6 \%)$ treatment interruptions. Compared to the 2004-2010 cohort, the 2011-2016 had a significantly $(p<0.05)$ higher rate of initiation ( 15.8 vs. 27.0 per 100 person-years, respectively). Age group, district category and duration of antiretroviral therapy emerged as the most significant predictors of IPT initiation, while district category and gender significantly predicted IPT therapy interruption.

Conclusion: These findings indicate a high uptake of IPT with a slow rate of implementation. Significant factors associated with disparities in the initiation and interruption of IPT therapy in this study are important for policy review.

Keywords: Cox's proportional hazards function; isoniazid preventive therapy; tuberculosis; uptake of health interventions; Lesotho.

\section{Introduction}

Human immunodeficiency virus (HIV) and tuberculosis (TB) have become a global syndemic responsible for nearly $25 \%$ of all HIV-associated deaths. ${ }^{1}$ The World Health Organization (WHO) ${ }^{1}$ notes that the incidence of TB in 2017 was about 133 cases per 100000 global population and of the 1.3 million people who died from TB in 2017 alone, 300000 were HIV-positive. Despite the considerable effectiveness of isoniazid preventive therapy (IPT), recommended by the $\mathrm{WHO}^{2}$ for the prevention of TB in people living with HIV (PLHIV), the rates of initiation and retention on IPT have generally been suboptimal, ${ }^{3,4,5,6}$ thus necessitating more population studies of this intervention.

The reasons for the slow implementation vary by country, with the most cited being poor health care delivery systems, underestimation of potential public health impact of IPT by HIV/TB programme managers and a lack of adequate means to exclude a pre-existing TB infection prior to treatment initiation, among others. ${ }^{7,9,10}$ Some countries were not convinced of the benefits of IPT and deferred the implementation of IPT altogether for many years. For example, the Ivory Coast had not implemented IPT by $2014 .{ }^{11}$

The uptake of health interventions, particularly in developing countries, is often slow. ${ }^{12}$ Scholars believe that this can be overcome by closing the 'know-do gap', that is, the gap between what is known and what gets implemented..$^{13,14,15}$ Further, Pablos-Mendez and Shademani ${ }^{15}$ note that 
slow IPT uptake in developing countries may be a symptom of a range of problems in the health systems of these countries, including a lack of evaluation studies. Therefore, the evaluation of IPT uptake is a crucial step to improving the implementation of IPT.

Lesotho is an independent country completely surrounded by South Africa, with about 2.2 million people and an estimated gross domestic product (GDP) per capita of $\$ 1000.00$, which puts the country into the low-income countries tier. ${ }^{16}$ With a $23.5 \%$ adult HIV prevalence rate, the country has the second highest prevalence rate of HIV worldwide $^{17}$ and with 665 TB incidences per 100000 population, ${ }^{1}$ the country is one of the top three nations with the highest rates of TB worldwide.

The Government of Lesotho (GoL) implemented the 6-month IPT guidelines of the WHO in 2011. ${ }^{18}$ However, ever since its launch, information on the rate of initiation of IPT and the associated factors has remained obscure. ${ }^{18}$ Of note, the country has not provided data for the IPT indicator to the WHO repository from the time the programme was launched. ${ }^{1}$ So, this study assessed the rate of initiation and retention of PLHIV on IPT and the associated factors in the high HIV/TB burden setting of Lesotho with the aim of identifying the barriers to the implementation of IPT in the country.

\section{Methods}

\section{Study setting}

Lesotho is divided into 10 administrative districts, five of which are densely populated and are considered scale-up districts for HIV/TB programmes. The scale-up districts occupy the lowlands of the country, while the other five (nonscale-up districts) occupy the mountainous sparsely populated highlands. ${ }^{19}$

Study participants were sampled from three district hospitals in three sparsely populated (non-scale-up) districts and five district hospitals from three densely inhabited (scale-up) districts of the country (see Figure 1).

\section{Study design}

This longitudinal retrospective cohort study analysed, based on Cox's proportional hazard regression, the probability of IPT initiation in PLHIV in Lesotho, considering time to IPT as the dependent variable. Further, the study assumed that the rate of IPT initiation was fairly constant and that the rate generally fitted an exponential curve that could be modelled by Cox's proportional hazards function. ${ }^{4}$

\section{Study population}

The target population was PLHIV enrolled into HIV care between 2004 and 2016 in the eight health institutions, all of which were district hospitals with at least 2000 patients on antiretroviral therapy (ART). Antiretroviral therapy records of HIV-positive children, adolescents and adults, including geriatric patients and pregnant women, were selected using stratified systematic random sampling across eight health facilities, ensuring proportional representation of all patient categories including gender, age and period of enrolment.

\section{Sample size calculation}

The minimum sample size was calculated following standard guidelines for estimating incidence with a specified relative precision. $^{20}$ The minimum number of patients' records, assuming a relative precision of $10 \%$ at $5 \%$ significance level, ${ }^{20}$ was 385 at each hospital or 3080 in the eight hospitals. However, an additional $40 \%$ were added to cater for incomplete records, implying that at least 4620 patient files were required.

\section{Patient sampling and data collection}

File selection was based on stratified systematic random sampling using a sampling frame that was prepared from the ART attendance registers by drawing a list of all the patients enrolled into HIV care since 2004. The total sample of files per hospital was obtained by dividing the total number of patients enrolled in HIV care by the proportional target sample size for the hospital.

Demographic and clinical data were captured between January and October 2016 from the paper-based ART and IPT registers into a Microsoft Access database (Microsoft, Richmond, United States) designed by the researchers. Overall, 4122 patient files were collected. Of the 4122 patients, 1167 were excluded according to the exclusion criteria presented in Figure 2.

\section{Patient data and outcome measures}

Time-variant variables such as age were calculated according to the time at enrolment into HIV care. Patients late for their scheduled appointments by more than a month and those who did not return for ART services were classified as loss to follow-up.

Time to IPT (in months) was calculated by subtracting the date of enrolment into HIV care from the date IPT was prescribed. Patient treatment outcomes were assessed by median cluster of differentiation 4 (CD4) and viral load values. The duration before ART commencement (in years), known as the pre-ART period, was calculated by subtracting the date of HIV diagnosis from that of ART commencement. Furthermore, the proportion of patients who had interrupted IPT therapy was also calculated and the factors associated with interrupting therapy were assessed using chi-square test and logistic regression analysis.

\section{Data preparation}

Data for IPT initiation in the database were verified and exported to Stata version 13.1 (StataCorp, TX, 


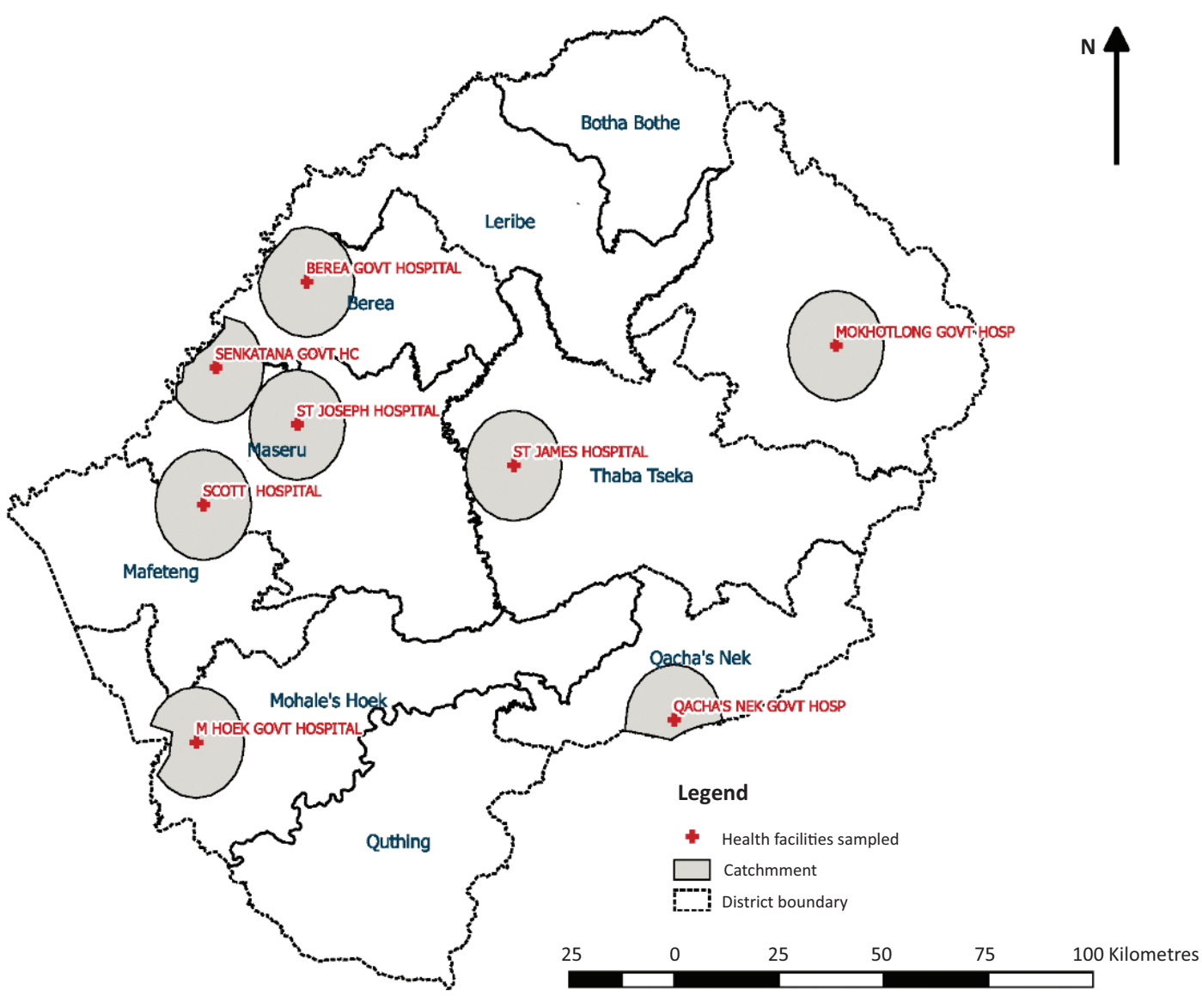

Note: Densely populated districts included in the study were Maseru, Berea and Mohale's Hoek, while sparsely populated districts sampled were Mokhotlong, Thaba-Tseka and Qacha's Nek. GOVT, government; HC, health centre; HOSP, hospital; M. HOEK, Mohale's Hoek.

FIGURE 1: Data collection sites.

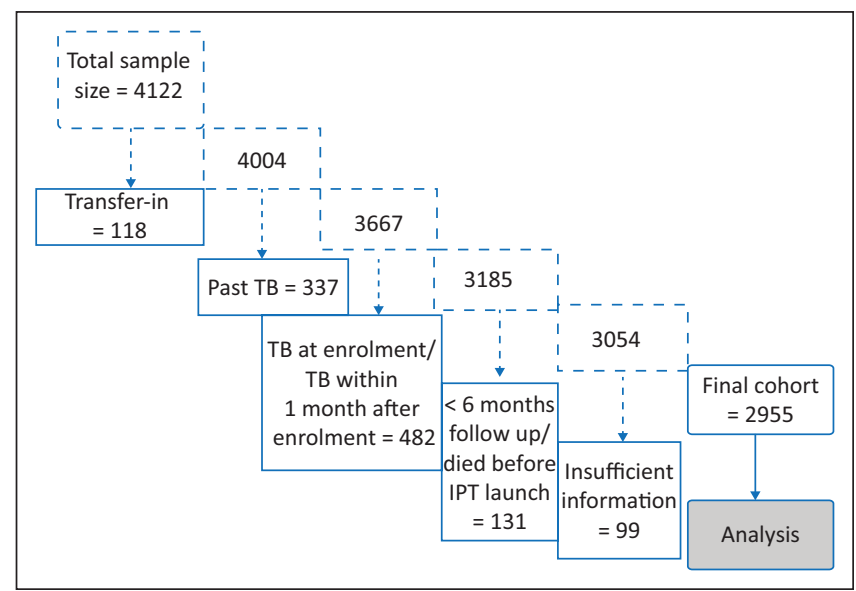

Note: Insufficient information referred to patient files with grossly missing data; past TB, having a diagnosis of TB before enrolment into HIV care.

TB, tuberculosis.

FIGURE 2: Exclusion criteria for the patients.

United States) for further cleaning and analysis. Data were formatted for survival analysis as discrete-time survival data with interval date as the time variable. The occurrence of the IPT event defined the 'failure' outcome with the time scale in years. To obtain comparable follow-up times, patients enrolled before IPT was available were declared to have entered the risk set in 2011, the year IPT was launched in the country. For purposes of calculating Cox's proportional hazards ratios, entry times into the risk set for all the patients were delayed by 1 month to calibrate for inconsistencies at first entry into the risk set. The date of enrolment into HIV care and the exit date marked the left and right censoring times, respectively.

\section{Analysing patient characteristics associated with isoniazid preventive therapy initiation}

The proportional 'hazard'21 in this study was the probability that an individual with certain characteristics would receive IPT in a specified time. To cater for observation gaps, followup times were subdivided into 6-month discrete intervals ${ }^{22}$ and Breslow's correction was used to correct for this treatment of data. ${ }^{21}$

Patient characteristics associated with IPT initiation were summarised by cross-tabulation. These characteristics were further analysed using univariate Kaplan-Meier survival functions to determine their suitability in the analysis model. Further, Wilcoxon's log-rank test and Cox regression 
analysis were used to determine equality across strata for categorical variables and continuous variables, respectively. Predictors with $p<0.2$ were included in the IPT initiation model.

The year 2011, when IPT was launched, was set as the base year for follow-up and medical records were stratified into the 2004-2010 cohort (before the launch of IPT) and the 2011-2016 cohort (after the launch of IPT). Ten predictors (see Table 1) were selected into the model and excluded using the stepwise method.

The model was tested for predictor interaction and two variables namely, duration of ART and the district category had significant interactions $(p<0.005)$. The models with and without the interaction variables were compared using the likelihood ratio test (Lrtest) and the difference was found to be significant (Chi [3] $=10.0 ; p=0.006)$, implying that the

TABLE 1: Associations between predictors and isoniazid preventive therapy initiation stratified by period of enrolment into human immunodeficiency virus care.

\begin{tabular}{|c|c|c|c|c|c|c|c|c|c|c|c|c|c|c|c|c|c|}
\hline \multirow[t]{3}{*}{ Variable } & \multicolumn{3}{|c|}{ Overall } & \multicolumn{7}{|c|}{ Enrolment period 2004-2010 } & \multicolumn{7}{|c|}{ Enrolment period 2011-2016 } \\
\hline & \multicolumn{2}{|c|}{$\begin{array}{l}\text { IPT } \\
\text { cases }\end{array}$} & \multirow{2}{*}{$\begin{array}{c}\text { IPT } \\
\text { cases/100 } \\
\text { person-years }\end{array}$} & \multirow{2}{*}{$\begin{array}{c}\text { Total } \\
(N)\end{array}$} & \multicolumn{2}{|c|}{$\begin{array}{l}\text { IPT cases } \\
\text { Row }\end{array}$} & \multirow{2}{*}{ Person-years } & \multirow{2}{*}{$\begin{array}{c}\text { IPT } \\
\text { cases } / 100 \\
\text { person-years } \dagger\end{array}$} & \multirow{2}{*}{ Chi-square } & \multirow[t]{2}{*}{$\mathbf{p}$} & \multirow[t]{2}{*}{$\begin{array}{c}\text { Total } \\
(N)\end{array}$} & \multicolumn{2}{|c|}{$\begin{array}{l}\text { IPT cases } \\
\text { Row }\end{array}$} & \multirow{2}{*}{ Person-years } & \multirow{2}{*}{$\begin{array}{c}\text { IPT } \\
\text { cases/100 } \\
\text { person-years }\end{array}$} & \multirow{2}{*}{ Chi-squared } & \multirow[t]{2}{*}{ p } \\
\hline & $\%$ & $N$ & & & $\%$ & $n$ & & & & & & $\%$ & $n$ & & & & \\
\hline Gender & - & - & & - & & - & - & - & 1.5 & 0.226 & - & - & - & - & - & 1.8 & 0.176 \\
\hline Female & 72 & 1394 & 21.1 & 798 & 77 & 613 & 3740 & 16.4 & - & - & 1144 & 68 & 781 & 2856 & 27.3 & - & - \\
\hline Male & 63 & 639 & 19.6 & 412 & 68 & 279 & 1901 & 14.7 & - & - & 601 & 60 & 360 & 1367 & 26.3 & - & - \\
\hline Age & - & - & - & & - & - & - & - & 3.1 & 0.373 & - & - & - & - & - & 4.3 & 0.23 \\
\hline Children & 40 & 21 & 10.7 & 31 & 42 & 13 & 135 & 9.6 & - & - & 21 & 38 & 8 & 61 & 13.2 & - & - \\
\hline Adolescents & 60 & 33 & 28.2 & 12 & 42 & 5 & 43 & 11.7 & - & - & 43 & 65 & 28 & 74 & 37.6 & - & - \\
\hline Adult & 69 & 1876 & 20.7 & 1116 & 75 & 839 & 5217 & 16.1 & - & - & 1587 & 65 & 1037 & 3849 & 26.9 & - & - \\
\hline Elderly & 71 & 103 & 21.2 & 51 & 69 & 35 & 246 & 14.2 & - & - & 94 & 72 & 68 & 239 & 28.4 & - & - \\
\hline District category & - & - & - & - & - & - & - & - & 0.9 & 0.336 & - & - & & - & - & 2.9 & 0.091 \\
\hline Sparse & 63 & 654 & 20.8 & 288 & 70 & 201 & 1375 & 14.6 & - & - & 754 & 60 & 453 & 1772 & 25.6 & - & - \\
\hline Adherence & - & - & - & - & - & - & - & - & 0.2 & 0.642 & - & - & - & - & - & 1.1 & 0.29 \\
\hline Good & 68 & 1581 & 21.7 & 843 & 75 & 620 & 3864 & 16.0 & - & - & 1493 & 68 & 961 & 3420 & 28.1 & - & - \\
\hline Poor & 73 & 452 & 17.5 & 367 & 74 & 272 & 1777 & 15.3 & - & - & 252 & 71 & 180 & 802 & 22.4 & - & - \\
\hline Treatment failure & - & - & - & - & - & - & - & - & 2.1 & 0.144 & - & - & - & - & - & 0.2 & 0.649 \\
\hline No & 69 & 1993 & 19.1 & 1176 & 73 & 860 & 5471 & 18.9 & - & - & 1733 & 65 & 1133 & 4184 & 27.1 & - & - \\
\hline Yes & 87 & 40 & 20.6 & 34 & 94 & 32 & 169 & 15.7 & - & - & 12 & 67 & 8 & 40 & 20.2 & - & - \\
\hline BL CD4 & - & - & - & - & - & - & - & - & 2.4 & 0.515 & - & - & - & - & - & 2.7 & 0.313 \\
\hline $1-100$ & 65 & 413 & 18.9 & 321 & 71 & 229 & 1449 & 15.8 & - & - & 318 & 59 & 186 & 757 & 24.6 & - & - \\
\hline $101-350$ & 72 & 1232 & 19.9 & 757 & 76 & 567 & 3582 & 15.8 & - & - & 957 & 70 & 666 & 2602 & 25.6 & - & - \\
\hline $351-500$ & 60 & 214 & 26.2 & 81 & 76 & 62 & 379 & 16.3 & - & - & 276 & 59 & 162 & 477 & 34.0 & - & - \\
\hline 501-1572 & 66 & 161 & 26.0 & 51 & 67 & 34 & 231 & 14.6 & - & - & 194 & 65 & 127 & 387 & 32.8 & - & - \\
\hline II & 69 & 842 & 18.7 & 609 & 71 & 430 & 2848 & 15.1 & - & - & 610 & 67 & 412 & 1664 & 24.7 & - & - \\
\hline III & 73 & 379 & 19.6 & 295 & 76 & 224 & 1355 & 16.5 & - & - & 221 & 70 & 155 & 577 & 26.8 & - & - \\
\hline IV & 46 & 79 & 19.1 & 60 & 70 & 42 & 245 & 17.1 & - & - & 111 & 33 & 37 & 169 & 21.9 & - & - \\
\hline Duration of pre-ART & - & - & - & - & - & - & - & - & 1.9 & 0.602 & - & - & - & - & - & 4.5 & 0.213 \\
\hline$<1$ & 70 & 1491 & 20.7 & 892 & 74 & 663 & 4151 & 15.9 & - & - & 1235 & 67 & 828 & 3050 & 27.2 & - & - \\
\hline $1-2$ & 74 & 198 & 21.1 & 121 & 76 & 92 & 561 & 16.4 & - & - & 148 & 72 & 106 & 377 & 28.1 & - & - \\
\hline $3-5$ & 67 & 229 & 19.2 & 135 & 76 & 102 & 654 & 15.6 & - & - & 209 & 56.4 & 127 & 538 & 23.6 & - & - \\
\hline$>5$ & 53 & 115 & 21.6 & 62 & 56 & 35 & 273 & 12.8 & - & - & 153 & 46.6 & 80 & 258 & 31.0 & - & - \\
\hline Duration of ART (years) & - & - & - & - & - & - & - & - & 24.0 & 0.000 & - & - & - & - & - & 9.4 & 0.024 \\
\hline $0-2$ & 45 & 329 & 59.4 & 59 & 2 & 1 & 40 & 2.4 & - & - & 678 & 48.4 & 328 & 514 & 63.8 & - & - \\
\hline $3-4$ & 67 & 479 & 23.7 & 63 & 32 & 20 & 191 & 10.4 & - & - & 654 & 70.2 & 459 & 1830 & 25.1 & - & - \\
\hline $5-6$ & 81 & 570 & 17.6 & 313 & 76 & 239 & 1499 & 15.9 & - & - & 388 & 85.3 & 331 & 1745 & 19.0 & - & - \\
\hline$>6$ & 82 & 655 & 16.2 & 775 & 81 & 632 & 3909 & 16.1 & - & - & 25 & 92.0 & 23 & 134 & 17.1 & - & - \\
\hline Total & 69 & 2033 & 20.6 & 1210 & 74 & 892 & 5641 & 15.8 & - & - & 1745 & 65 & 1141 & 4223 & 27.0 & 300 & $0.000 \uparrow$ \\
\hline
\end{tabular}

Note: $\mathrm{CD} 4$ counts are in cells $/ \mathrm{mm}^{3}$.

ART, antiretroviral therapy; BL, baseline; IPT, isoniazid preventive therapy; $N$, number of patients; TB, tuberculosis; tnd, target not detected; WHO, World Health Organization. CD4 counts are in cells $/ \mathrm{mm}^{3}$.

$\dagger$, The observation time in 100 person-years is only for tallying purposes because IPT was launched in 2011 
bigger model with the interaction terms was superior to the one without.

The unstratified model was checked for proportionality using the Schoenfeld and scaled Schoenfeld residuals (Phtest) test. One categorical variable, duration of ART significantly $(p=0.032)$, violated the proportionality assumption, but was, however, retained in the model and the anomaly corrected through stratification with period of enrolment.

\section{Ethical considerations}

The study was approved by the Ethics Committee of the Ministry of Health of Lesotho. Permission to conduct the study was also granted by the hospital authorities. Fictional identifier codes were assigned to the patients in the database and all patient data were treated with confidentiality.

\section{Results}

\section{Associations between incident isoniazid preventive therapy initiation and predictor variables}

In total, 2955 patients were included in the final analysis (see Appendix 1, Table 1-A1, for extended patient characteristics cross-tabulated with IPT initiation outcome). Table 1 presents the overall incident IPT cases and the cases stratified by period of enrolment. By proportion, $68.8 \%$ of the patients received IPT during follow-up, while $31.2 \%$ had not received the drug at the exit time for the study. Overall, 2033 incident IPT cases in 9728 person-years of observation occurred out of the 2955 patients in the study. The overall rate of IPT initiation was 20.6 per 100 person-years. The effective follow-up time since IPT was launched in 2011 ranged from 0.5 to 5.8 years [mean $=3.5$; median $=4.1$; interquartile range [IQR]: 1.4-5.6]. With the data stratified by period of enrolment, the median time to IPT for the patients enrolled before 2011 was higher than that of the patients enrolled on ART after 2011 (4.8 vs. 2.5 years, respectively). Compared to patients enrolled before 2011, patients enrolled after 2011 had a significantly ( $p=$ 0.000 ) higher initiation rate (15.8 vs. 27.0 per 100 personyears, respectively).

Four variables, namely gender, antiretroviral treatment failure, baseline WHO clinical stage and duration on ART, had considerable association $(p<0.300)$ with IPT initiation in the patients enrolled on ART before 2011. However, for the patients enrolled on ART after 2011, more variables, namely, gender, age, district category, adherence, baseline WHO clinical stage, duration on pre-ART and duration on ART had substantial influence $(p<0.300)$ on IPT initiation.

Figures 3(a) and 3(b) depict the predictive effect of selected variables in Table 1 on IPT initiation based on the KaplanMeier failure function of time to IPT initiation per predictor variable. Period of enrolment and district category were disproportionate, which justified the need for stratified analysis with period of enrolment as the strata variable to correct this anomaly.

Significant $(p<0.2)$ categorical predictor variables that had distinct plots were namely: (1) gender, (2) marital status, (3) district, (4) geographic location, (5) period of enrolment into HIV care, (6) baseline WHO clinical stage, (7) adherence to ART, (8) patient status at exit time of the study and (9) history of past TB infection on first visit. For continuous predictors, significant $(p<0.2)$ predictors (in Table 1) that also had distinct plots (Figures $3 a$ and 3b) were namely: (1) age, (2) baseline CD4 count, (3) median CD4 count, (4) median viral load and (5) duration of pre-ART.

\section{Associations between patient characteristics and interrupting isoniazid preventive therapy}

Table 2 presents the associations between patient characteristics and interrupting IPT therapy. Gender and the district density category were significantly $(p<0.050)$ associated with interrupting IPT by chi-square test, while baseline CD4 count was only marginally significant $(t=7.6$; $p=0.056)$. Multiple logistic regression analysis revealed that although baseline CD4 count category 351 cells $/ \mathrm{mm}^{3}-$ 500 cells $/ \mathrm{mm}^{3}$ (odds ratio [OR]: $2.2 ; 95 \%$ confidence interval [CI]: $1.2-4.0 ; p=0.013$ ) and baseline WHO clinical stage IV (OR: 2.5; 95\% CI: 1.2-5.1; $p=0.015$ ) were also significant, sparsely populated district category (adjusted OR: 1.6; 95\% CI: $1.1-2.3 ; p=0.000$ ) and gender (adjusted OR: $2.1 ; 95 \%$ CI: 1.5 3.0; $p=0.006)$ were the most influential in determining interruption of IPT therapy.

\section{The rate of initiation of isoniazid preventive therapy}

Out of 10 variables considered for inclusion in the model, three predictors, district category, age group and duration on ART emerged as significant $(p<0.050)$ predictors (Table 3$)$. Two predictors, duration on ART and district category, had significant $(p=0.000)$ interactions (shown as duration on ART \# District category in Table 3).

In the final model stratified by period of enrolment into HIV care (Table 3), considering the patients enrolled on ART before 2011, the following findings were noted: (1) adults had a $64 \%$ higher probability of receiving IPT (Hazard Ratio $[\mathrm{HR}]=1.64 ; 95 \% \mathrm{CI}: 1.02-2.61)$ in relation to children and adolescents, (2) the likelihood of receiving IPT did not statistically differ between patients in the densely populated districts $(\mathrm{HR}=1.03 ; 95 \% \mathrm{CI}: 0.46-2.30)$ and those in the sparsely populated regions and (3) longer durations on ART were associated with higher chances of IPT uptake. For example, patients on ART for 5 or more years were three times more likely to receive IPT compared to patients on ART for less than 5 years (HR $=3.34 ; 95 \% \mathrm{CI}$ : 2.06-5.43). However, comparing two subjects on ART for 5 or more years in the densely populated districts and considering the 

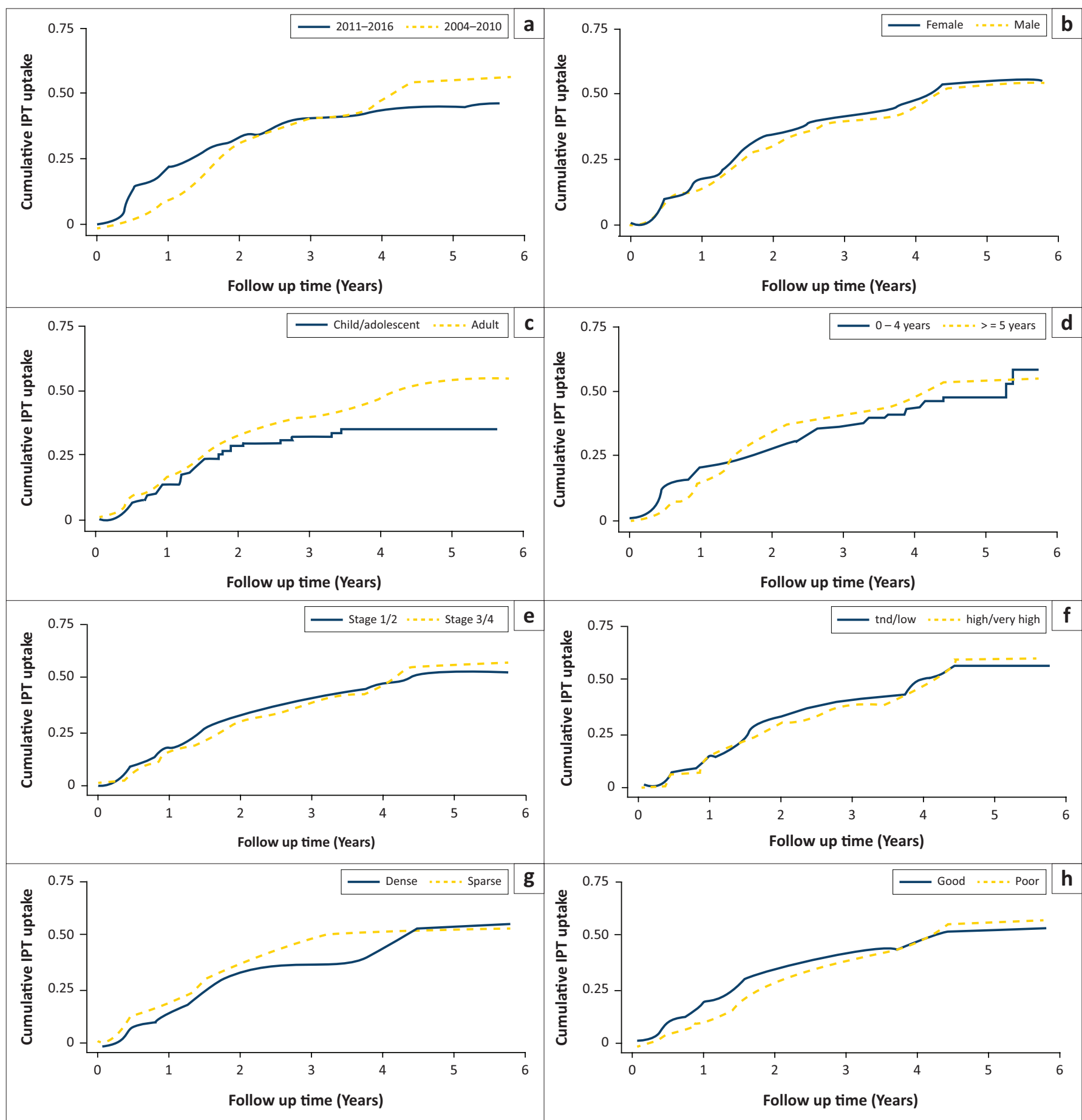

ART, antiretroviral therapy; IPT, isoniazid preventive therapy; WHO, World Health Organization; HIV, human immunodeficiency virus.

FIGURE 3: (a) Kaplan-Meier function of time to isoniazid preventive therapy initiation by predictor variables. Age group (c) and duration of antiretroviral therapy (d) were important determinants of isoniazid preventive therapy initiation, while gender (b) was not. Baseline World Health Organization clinical stage (e), median viral load (f), district category $(\mathrm{g})$ and adherence $(\mathrm{h})$ were all important predictors of isoniazid preventive therapy initiation.

interaction terms, having 5 or more years of ART was $20 \%$ more likely to receive IPT compared to patients on ART for less than 5 years.

Considering the patients enrolled in the 2011-2016 period, notable trends were as follows: (1) adults had $78 \%$ higher probability of receiving IPT (HR $=1.78 ; 95 \% \mathrm{CI}$ : $1.00-3.15)$ in relation to children and adolescents; (2) patients in the densely populated districts had 59\% lower likelihood of receiving IPT $(\mathrm{HR}=0.59 ; 95 \% \mathrm{CI}: 0.38-0.94)$ compared to the sparsely populated districts and (3) longer durations on ART were still associated with higher chances of IPT initiation. For instance, patients on ART for 5 or more years were $33 \%$ more likely to receive IPT compared to patients on ART for less than 5 years $(\mathrm{HR}=1.33$; 95\% CI: 1.00-1.76). However, comparing two subjects on ART for 5 or more years in the densely populated districts and taking into account the interaction terms, having 5 or more years of ART was 34\% more likely to receive IPT compared to patients on ART for less than 5 years. 
TABLE 2: Association between patient characteristics and isoniazid preventive interrupted therapy.

\begin{tabular}{|c|c|c|c|c|c|c|c|c|c|c|c|}
\hline \multirow[t]{2}{*}{ Patient characteristic } & \multirow[t]{2}{*}{ Total $(n)$} & \multicolumn{2}{|c|}{ Interrupted IPT } & \multirow[t]{2}{*}{ Chi-square } & \multirow[t]{2}{*}{$p$} & \multicolumn{3}{|c|}{ Univariate } & \multicolumn{3}{|c|}{ Multivariate } \\
\hline & & Row \% & $n$ & & & Unadjusted OR & $(95 \% \mathrm{Cl})$ & $p$ & Adjusted OR & $(95 \% \mathrm{Cl})$ & $p$ \\
\hline Age & - & - & - & 4.1 & 0.765 & Excluded & - & - & Excluded & - & - \\
\hline $0-9$ & 21 & 0 & 0 & - & - & - & - & - & - & - & - \\
\hline $9-18$ & 22 & 9.1 & 2 & - & - & - & - & - & - & - & - \\
\hline $18-25$ & 179 & 5.6 & 10 & - & - & - & - & - & - & - & - \\
\hline $25-35$ & 691 & 6.2 & 43 & - & - & - & - & - & - & - & - \\
\hline $35-45$ & 598 & 7.4 & 44 & - & - & - & - & - & - & - & - \\
\hline $45-55$ & 338 & 7.7 & 26 & - & - & - & - & - & - & - & - \\
\hline $55-65$ & 151 & 6 & 9 & - & - & - & - & - & - & - & - \\
\hline $65-84$ & 33 & 3 & 1 & - & - & - & - & - & - & - & - \\
\hline Gender & - & - & - & 7.8 & 0.005 & base & 1 & - & base & 1 & - \\
\hline Female & 1394 & 5.6 & 78 & - & - & - & - & - & - & - & - \\
\hline Male & 639 & 8.9 & 57 & - & - & 1.7 & $1.2-2.4$ & 0.006 & 1.7 & $1.5-3.0$ & 0.006 \\
\hline Geographic location & - & - & - & 18.5 & 0.000 & base & 1 & - & base & 1 & - \\
\hline Dense & 1379 & 5 & 69 & - & - & - & - & - & - & - & - \\
\hline Sparse & 654 & 10.1 & 66 & - & - & 2.1 & $1.5-3.0$ & 0.000 & 1.6 & $1.1-2.3$ & 0.000 \\
\hline Period enrolled into HIV care & - & - & - & 0.2 & 0.689 & base & 1 & 0.689 & Excluded & - & - \\
\hline 2011-2016 & 1141 & 6.8 & 78 & - & - & - & - & - & - & - & - \\
\hline 2004-2010 & 892 & 6.4 & 57 & - & - & 1.1 & $0.8-1.5$ & - & - & - & - \\
\hline Baseline WHO clinical stage & - & - & - & 7.6 & 0.056 & base & - & base & - & - & - \\
\hline 1 & 733 & 6.4 & 47 & - & - & - & - & - & - & - & - \\
\hline 2 & 842 & 6.7 & 56 & - & - & 1.0 & $0.7-1.6$ & 0.848 & 1.3 & $0.9-2.1$ & 0.174 \\
\hline 3 & 379 & 5.5 & 21 & - & - & 0.9 & $0.5-1.5$ & 0.566 & 1.1 & $0.6-2.0$ & 0.688 \\
\hline 4 & 79 & 13.9 & 11 & - & - & 2.4 & $1.2-4.8$ & 0.016 & 2.5 & $1.2-5.1$ & 0.015 \\
\hline BL CD4 count & - & - & - & 13.1 & 0.004 & base & 1 & base & 1 & - & - \\
\hline $1-100$ & 415 & 5.8 & 24 & - & - & - & - & - & - & - & - \\
\hline $101-350$ & 1233 & 5.7 & 70 & - & - & 0.9 & $0.6-1.6$ & 0.936 & 1.1 & $0.6-1.7$ & 0.828 \\
\hline $351-500$ & 224 & 11.6 & 26 & - & - & 2.1 & $1.2-3.8$ & 0.010 & 2.2 & $1.2-4.0$ & 0.013 \\
\hline 501-1512 & 161 & 9.3 & 15 & - & - & 1.7 & $0.9-3.3$ & 0.133 & 2.0 & $2.0-3.9$ & 0.060 \\
\hline
\end{tabular}

Note: $\mathrm{CD} 4$ counts are in cells $/ \mathrm{mm}^{3}$.

IPT, isoniazid preventive therapy; $n$, number of patients; ART, antiretroviral therapy; BL, baseline; WHO, World Health Organization; HIV, human immunodeficiency virus; OR, odds ratio; Cl, confidence interval.

\section{Discussion}

The study found a high IPT uptake (68.8\%) with generally a slow IPT initiation rate of 20.6 per 100 person-years. This indicates that despite the majority of PLHIV getting initiated on IPT, the rate of IPT implementation remains slow. More importantly, this study also indicates the need for reporting the rate of initiation for IPT in addition to national coverage statistics as is the current practice globally. Currently, data on rate IPT initiation are scarce, with only Brazil reporting such data - the rate of initiation in that country was 20.0 per 100 person-years in $2014 .{ }^{4}$ Widespread tracking of the rate of initiation for IPT in developing countries would certainly need more bioinformatic tools and skills that are often lacking in these countries.

Despite the lack of comparable data on the rate of IPT initiation from other countries in the southern African region and beyond, IPT coverage in Lesotho is commendable and encouraging. To put IPT coverage for Lesotho into perspective, $\mathrm{WHO}^{1}$ reports that national coverage for IPT in 15 of the 30 high HIV/TB burden countries ranged from 1\% in Swaziland to 53\% in South Africa. Other countries in subSaharan Africa with IPT coverage higher than 30\% include Ethiopia (45\%), Nigeria (39\%), Sierra Leone (22\%), Zambia (18\%), Namibia (15\%) and Angola (13\%). Notably, IPT coverage in many sub-Saharan countries, such as Botswana,
Malawi, Ghana and Uganda, was unknown in 2017. ${ }^{1}$ Therefore, considering the high TB burden in Lesotho, there is need to maintain the high uptake rate for IPT while improving the slow rate of initiation to ensure that newly ART-initiated patients are given IPT as early as possible. ${ }^{23}$

Given that IPT is projected to be more effective in high TB burden countries when optimally implemented, ${ }^{24}$ this study further highlights that Lesotho is losing the opportunity to control TB through IPT. With an incidence rate of TB exceeding 600 cases/100 000 population, ${ }^{24}$ Lesotho needs to intensify the scaling up of IPT.

The median time to IPT for the 2004-2010 cohort was almost twice as high as that of the 2011-2016 cohort, implying that the patients enrolled on ART after IPT was launched have a higher initiation rate in this setting. This disparity therefore needs to be addressed.

The fact that children and adolescents had a lower chance of IPT initiation compared to adults in both the 2004-2010 and 2011-2016 cohorts emphasises the need for scale-up efforts for these patient groups. Tadesse et al. ${ }^{7}$ and Triasih et al. ${ }^{25}$ in Ethiopia and Indonesia, respectively, note that children in resource-limited high ТB burden settings have a low initiation rate of IPT despite that a 6-month course of IPT reduces the risk of childhood TB by the same margin of about 
TABLE 3: Cox proportional hazards model for initiation of isoniazid preventive therapy by people living with human immunodeficiency virus in Lesotho.

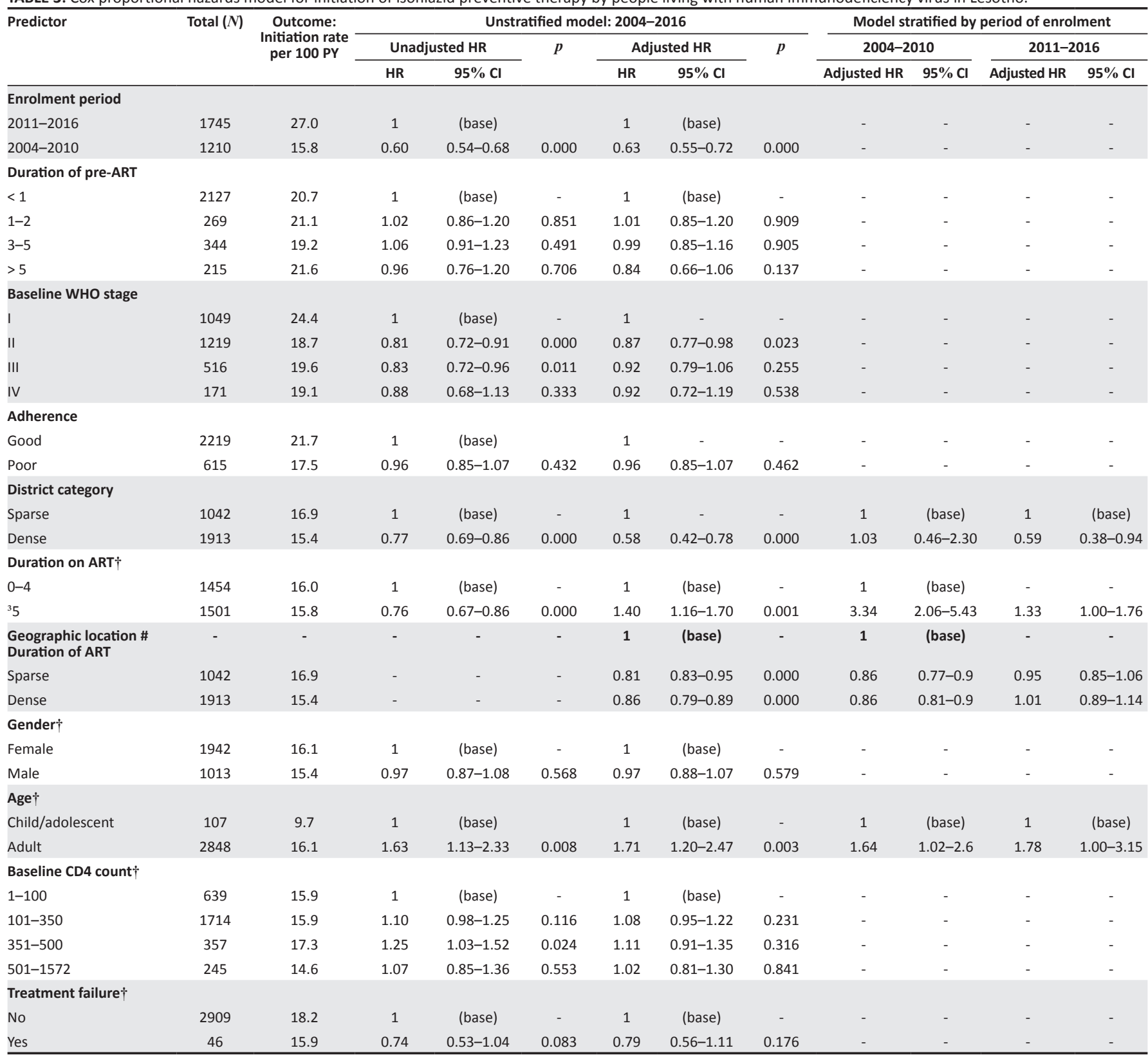

WHO, World Health Organization; ART, antiretroviral therapy; N, number of patients; PLHIV, people living with HIV; \# denotes interaction of term; Cl, confidence interval; HR, Hazard Ratio.

$\dagger$, Predictors insignificant when controlled for baseline WHO clinical Stage, duration of ART, district category and adherence to ART.

$60 \%$ as adults. Lesotho therefore needs to scale-up TB contact screening as recommended by WHO. ${ }^{23}$ Deficiencies for the identification of children in need of IPT have also been reported in Brazil, Benin and Indonesia, ${ }^{25,26,27}$ and these include health care worker and health facility-related factors, including social support and access.

Isoniazid preventive therapy initiation in the densely populated districts was much lower in the 2011-2016 cohort. Access to HIV/TB services including IPT in the densely populated districts has generally been slow because of a number of reasons including resource limitations for scaleup efforts in these areas that have an estimated $72 \%$ of the country's population. ${ }^{19}$ The lower initiation rates in the densely populated districts indicate that IPT scale-up efforts, currently supported by President's Emergency Plan for AIDS
Relief (PEPFAR) Lesotho, 19 need to be intensified in these districts.

Interrupting of IPT therapy in this study was associated with staying in the sparsely populated districts, being male, having baseline CD4 count of 351 cells $/ \mathrm{mm}^{3}-500$ cells $/ \mathrm{mm}^{3}$ and baseline WHO clinical stage IV. Patients in the sparsely populated districts, particularly those who are bedridden and in WHO clinical stage IV, may be interrupting therapy because of long distances from the hospitals and the mountainous terrain associated with these geographic locations. Scaling up health care delivery in these areas is therefore needed to reduce therapy interruption. In South Africa, inefficient health service delivery, ineffective communication with health care workers and the financial burden of transport to clinic were the most significant factors 
for interrupting IPT therapy. ${ }^{28}$ Higher rates of treatment interruption among men emphasise the need for intensified patient education in this group. In Botswana, men also had more interrupted IPT therapy than women. ${ }^{29}$

A qualitative assessment of the factors contributing to low IPT initiation is required in this setting. Of note, barriers to IPT implementation in other settings include health care worker inexperience, unawareness of the benefits of IPT, as well as poor understanding of IPT guidelines and TB screening tools. ${ }^{30}$ Therefore, there is a need to assess the effect of health care worker factors on implementation of IPT in Lesotho.

Of note, in some African countries such as the Ivory Coast, the national guidelines had not started using IPT by 2014, citing that IPT could lead to resistant TB bacilli in patients with undiagnosed TB. ${ }^{11}$ This highlights the magnitude of the challenge of scaling up this intervention in developing countries.

This study is not without limitations, one of which is the lack of data on patient views. As Ostermann et al. ${ }^{12}$ note, interventions must factor in the preferences of the intended target populations to improve initiation and adherence to the intervention. Therefore, investigations on patient preferences and concerns about IPT are needed in Lesotho. However, the main strength of this study is the reporting of IPT initiation in person-years which allows comparisons with other settings outside Lesotho. This study also demonstrates that routine data in ART programmes of developing countries can be useful for inferential analysis.

\section{Conclusion}

This study investigated the rate of IPT initiation from the time the IPT programme was launched in 2011 in a high TB burden setting of Lesotho. Despite the high overall IPT uptake, the rate of IPT initiation was slow. The slow initiation of IPT is disconcerting and the factors associated with poor rate of initiation in this study need to be addressed. The high rate of IPT treatment interruption in the sparsely inhabited districts is evidence to the need to improve the monitoring of this programme. Clearly, the implementation of this health intervention in a high TB burden setting of Lesotho needs further scale-up.

\section{Acknowledgement}

The authors would like to thank individuals who assisted with compiling of data for this study.

\section{Competing interests}

The authors declare that they have no financial or personal relationships that may have inappropriately influenced them in writing this article.

\section{Authors' contributions}

E.M. conceptualised and designed the study, acquired data, interpreted the data, and drafted the manuscript for publication. D.O. and W.M.J.v.d.H. made substantial contributions to the design, analysis, interpretation of data, and revision of the manuscript. All the authors gave final approval of the final version to be published.

\section{Funding information}

This work was funded by a research grant from the Central University of Technology, South Africa.

\section{Data availability statement}

Data sharing is not applicable to this article as no new data were created or analysed in this study.

\section{Disclaimer}

The views and opinions expressed in this article are those of the authors and do not necessarily reflect the official policy or position of any affiliated agency of the authors.

\section{References}

1. WHO. Global tuberculosis report 2018. Geneva: World Health Organization; 2018.

2. WHO. Interim policy on collaborative TB/HIV activities. Geneva: WHO Press; 2004.

3. Ayele HT, Mourik MSV, Bonten M. Predictors of adherence to isoniazid preventive therapy in HIV patients in Ethiopia: A prospective cohort study. Int J Infect Dis. 2016;45:386-386.

4. Dowdy DW, Golub JE, Saraceni V, et al. Impact of isoniazid preventive therapy for HIV-infected adults in Rio de Janeiro, Brazil: An epidemiological model. J Acquir Immune Defic Syndr. 2014;66(5):552-558.

5. Tedla Z, Nguyen ML, Sibanda T, et al. Isoniazid-associated hepatitis in adults infected with HIV receiving 36 months of isoniazid prophylaxis in Botswana. Chest. 2015;147(5):1376-1384. https://doi.org/10.1378/chest.14-0215

6. Sumner T, Houben R, Rangaka MX, et al. Post-treatment effect of isoniazid preventive therapy on tuberculosis incidence in HIV-infected individuals on antiretroviral therapy. AIDS. 2016;30(8):1279-1286. https://doi.org/10.1097/ QAD.0000000000001078

7. Tadesse Y, Gebre N, Daba S, et al. Uptake of isoniazid preventive therapy among under-five children: TB contact investigation as an entry point. PLoS One. 2016;11(5):e0155525.

8. Assebe LF, Reda HL, Wubeneh AD, Lerebo WT, Lambert SM. The effect of isoniazid preventive therapy on incidence of tuberculosis among HIV-infected clients under
pre-ART care, Jimma, Ethiopia: A retrospective cohort study. BMC Public Health. 2015(1);15:346. https://doi.org/10.1186/s12889-015-1719-0

9. Guwatudde D, Debanne SM, Diaz M, King C, Whalen C. A re-examination of the potential impact of preventive therapy on the public health problem of tuberculosis in contemporary sub-Saharan Africa. P
doi.org/10.1016/j.ypmed.2004.04.008

10. Ayele HT, Van Mourik MS, Bonten MJ. Effect of isoniazid preventive therapy on tuberculosis or death in persons with HIV: A retrospective cohort study. BMC Infect Dis. 2015;15(1):334. https://doi.org/10.1186/s12879-015-1089-3

11. Temprano ANRS 12136 Study Group. A trial of early antiretrovirals and isoniazid preventive therapy in Africa. N Engl J Med. 2015;2015(373):808-822. https://doi. org/10.1056/NEJMoa1507198

12. Ostermann J, Brown DS, De Bekker-Grob EW, Mühlbacher AC, Reed SD. Preferences for health interventions: Improving uptake, adherence, and efficiency. Patient. 2017:10(4):511-514. https://doi.org/10.1007/s40271-017-0251-y

13. Yamey G. What are the barriers to scaling up health interventions in low and middle income countries? A qualitative study of academic leaders in implementation science. Global Health. 2012;8(1):11. https://doi.org/10.1186/ 1744-8603-8-11

14. Bragge P, Grimshaw JM, Lokker C, Colquhoun H. AIMD - a validated, simplified framework of interventions to promote and integrate evidence into health practices, systems, and policies. BMC Med Res Methodol. 2017;17(1):38. https:// doi.org/10.1186/s12874-017-0314-8

15. Pablos-Mendez A, Shademani R. Knowledge translation in global health. J Cont Educ Health Prof. 2006;26(1):81-86. https://doi.org/10.1002/chp.54

16. BOS. Lesotho 2016 census of population and housing preliminary report. Maseru: Government Printers; 2017.

17. UNAIDS. UNAIDS Spectrum 2016 [www.unaids.org]. 2016 [cited 2017 Mar 19]; Available from: http://www.unaids.org/en/dataanalysis/datatools/spectrumepp

18. GoL. National TB and Leprosy Control Strategic Plan 2013-2017. Maseru: Government of Lesotho; 2013. 
19. PEPFAR Lesotho. Lesotho Country Operational Plan (COP) 2016 Strategic Direction Summary [/www.pepfargov] [homepage on the Internet]. 2016 [cited 2017 Mar 07]; Available from: https://www.pepfar.gov/documents/organization/257640.pdf.

20. Lwanga SK, Lemeshow S. Sample size determination in health studies. London: WHO Publication; 1991.

21. Kleinbaum DG, Klein M. Survival analysis: A self-learning text. 2nd ed. New York: Springer; 2005.

22. Singer JD, Willett JB. Applied longitudinal data analysis: Modeling change and event occurrence. New York: Oxford University Press; 2003.

23. WHO. Global tuberculosis report 2015. WHO/HTM/TB/2015.22. Geneva, WHO Press; 2015.

24. Ragonnet R, Trauer JM, McBryde ES, et al. Is IPT more effective in high-burden settings? Modelling the effect of tuberculosis incidence on IPT impact. Int J Tuberc Lung Dis. 2017;21(1):60-66. https://doi.org/10.5588/ijtld.16.0297

25. Triasih R, Padmawati RS, Duke T, Robertson C, Sawyer SM, Graham SM. A mixed-methods evaluation of adherence to preventive treatment among child tuberculosis contacts in Indonesia. Int J Tuberc Lung Dis. 2016;20(8):1078-1083.
26. Mendonca AMC, Kritski AL, Sant'Anna CC. Tuberculosis contact tracing among children and adolescents referred to children's hospital in Rio de Janeiro, Brazil. Braz J Infect Dis. 2015;19(3):296-301.

27. Adjobimey M, Masserey E, Adjonou C, et al. Implementation of isoniazid preventive therapy in children aged under 5 years exposed to tuberculosis in Benin. Int J Tuberc Lung Dis. 2016;20(8):1055-1059. https://doi.org/10.5588/ ijtld.15.0493

28. Jacobson KB, Niccolai L, Mtungwa N, Moll AP, Shenoi SV. 'It's about my life': facilitators of and barriers to isoniazid preventive therapy completion among people living with HIV in rural South Africa. AIDS Care. 2017:29(7):936-942. https://doi.org/10.1080/09540121.2017.1283390

29. Mokwena K, Motsamai O. A profile of isoniazid tuberculosis preventive therapy treatment defaulters in Botswana: Utilization of primary health care services. Afr J Phys Health Educ Recreation Dance. 2015;21(Suppl. 2):268-274.

30. Lester R, Hamilton R, Charalambous $S$, et al. Barriers to implementation of isoniazid preventive therapy in HIV clinics: A qualitative study. AIDS. 2010;24 (Suppl 5):S45-S48. https://doi.org/10.1097/01.aids.0000391021.18284.12 


\section{Appendix 1}

TABLE 1-A1: Associations between patient characteristics and isoniazid preventive therapy initiation in people living with human immunodeficiency virus in Lesotho. Variable

Received IPT while in HIV care

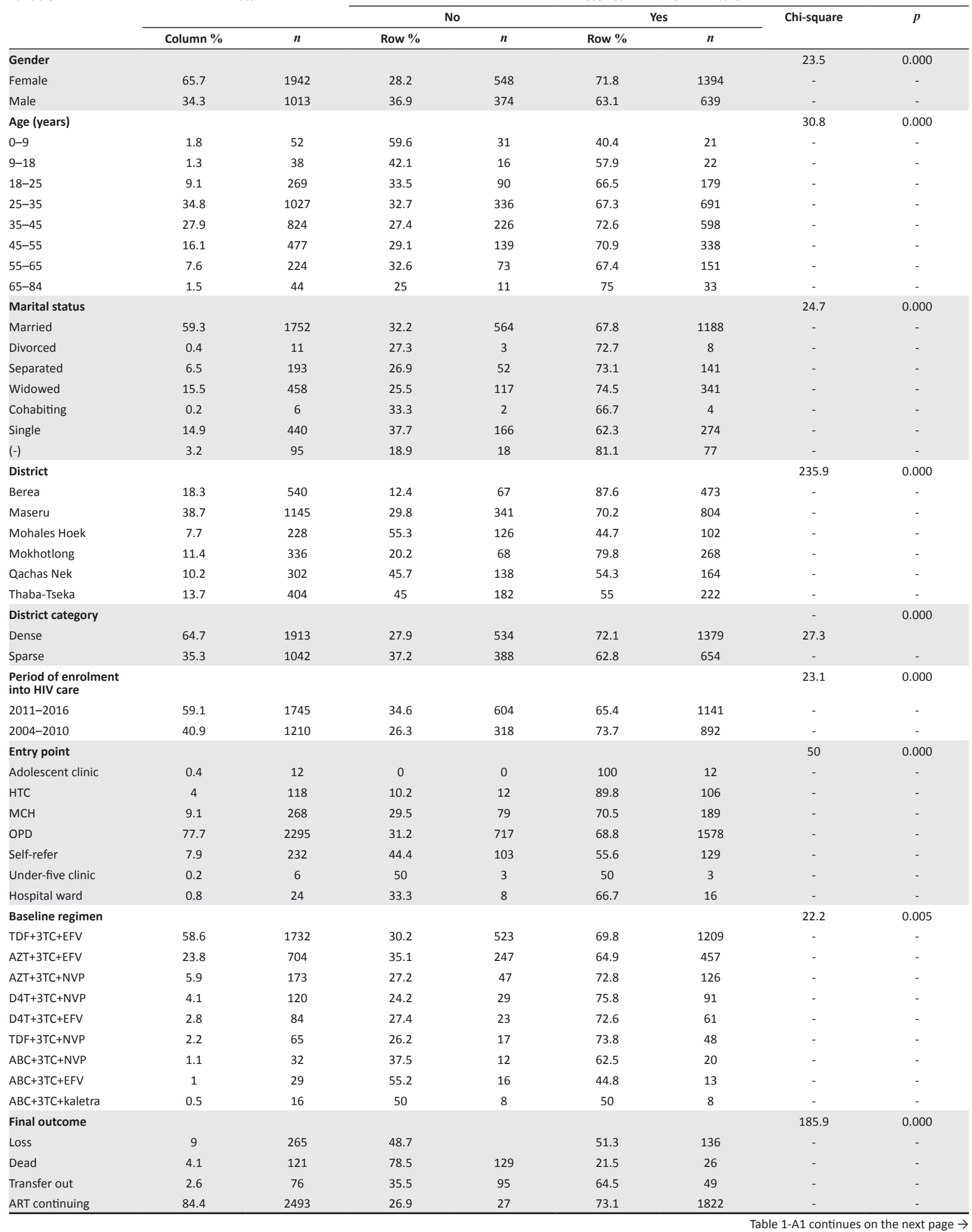


TABLE 1-A1 (Continues...): Associations between patient characteristics and isoniazid preventive therapy initiation in people living with human immunodeficiency virus in Lesotho. Variable

\begin{tabular}{|c|c|c|c|c|c|c|c|c|}
\hline \multirow[t]{3}{*}{ variadie } & \multirow{2}{*}{\multicolumn{2}{|c|}{ Iotal }} & \multicolumn{6}{|c|}{ Recelvea Ir I While in Hiv care } \\
\hline & & & \multicolumn{2}{|c|}{ No } & \multicolumn{2}{|c|}{ Yes } & \multirow[t]{2}{*}{ Chi-square } & \multirow[t]{2}{*}{$p$} \\
\hline & Column \% & $n$ & Row \% & $n$ & Row \% & $n$ & & \\
\hline Adherence to ART & & & & & & & 6.5 & 0.011 \\
\hline Good & 79.1 & 2336 & 32.3 & 755 & 67.7 & 1581 & - & - \\
\hline Poor & 20.9 & 619 & 27 & 167 & 73 & $(452$ & - & - \\
\hline Treatment failure & & & & & & & 7.2 & 0.007 \\
\hline No & 98.4 & 2909 & 31.5 & 916 & 68.5 & 1993 & - & - \\
\hline Yes & 1.6 & 46 & 13 & 6 & 87 & 40 & - & - \\
\hline BL CD4 count & & & & & & & 19.5 & 0.000 \\
\hline $1-100$ & - & - & 35.1 & 224 & 64.9 & 415 & - & - \\
\hline $101-350$ & - & - & 28.1 & 481 & 71.9 & 1233 & - & - \\
\hline $351-500$ & - & - & 37.3 & 133 & 62.7 & 224 & - & - \\
\hline 501-1512 & - & - & 34.3 & 84 & 65.7 & 161 & - & - \\
\hline BL WHO clinical stage & & & & & & & 46.5 & 0.000 \\
\hline I & - & - & 30.1 & 316 & 69.9 & 733 & - & - \\
\hline 11 & - & - & 30.9 & 377 & 69.1 & 842 & - & - \\
\hline III & - & - & 26.6 & 137 & 73.4 & 379 & - & - \\
\hline IV & - & - & 53.8 & 92 & 46.2 & 79 & - & - \\
\hline Median viral load & & & & & & & 14.7 & 0.005 \\
\hline Tnd $\dagger$ & 9.1 & 268 & 24.3 & 65 & 75.7 & 203 & - & - \\
\hline Low & 1.3 & 38 & 34.2 & 13 & 65.8 & 25 & - & - \\
\hline High & 2.1 & 61 & 31.1 & 19 & 68.9 & 42 & - & - \\
\hline Very high & 2.8 & 84 & 17.9 & 15 & 82.1 & 69 & - & - \\
\hline$(-)$ & 84.7 & 2504 & 32.3 & 810 & 67.7 & 1694 & - & - \\
\hline Length of pre-ART (years) & & & & & & & 28.8 & 0.000 \\
\hline$<1$ & 72 & 2127 & 29.9 & 636 & 70.1 & 1491 & - & - \\
\hline $01-2$ & 9.1 & 269 & 26.4 & 71 & 73.6 & 198 & - & - \\
\hline $03-5$ & 11.6 & 344 & 33.4 & 115 & 66.6 & 229 & - & - \\
\hline$>5$ & 7.3 & 215 & 46.5 & 100 & 53.5 & 115 & - & - \\
\hline Total & 100 & 2955 & 31.2 & 922 & 68.8 & 2033 & - & - \\
\hline
\end{tabular}

(-), missing information; ART, antiretroviral therapy; ABC, abacavir; AZT, zidovudine; 3TC, lamivudine; kaletra, lopinavir or ritonavir; NVP, nevirapine; EFV, efavirenz; TDF, tenofovir; BL, baseline; HTC, HIV testing and counselling; $\mathrm{MCH}$, mother and child health; OPD, outpatient department.

$\dagger$, Tnd, target not detected; WHO, World Health Organization; CD4 counts are in cells $/ \mathrm{mm}^{3}$; viral load ranges in copies/mm ${ }^{3}$ are as follows; tnd (0-50); low (50-500); high (500-10 000) and very high (>10 000). 